\title{
Common Characteristics of Power Conversion Circuits - Topology, Function and Power Semiconductor Switches
}

\author{
Viktor ŠUNDE*, Željko JAKOPOVIĆ, Zvonko BENČIĆ, Denis PELIN
}

\begin{abstract}
Experience in teaching of power electronics courses shows that at the beginning of the study students do not understand the common background of power conversion circuits. Students think that the topology of a converter circuit exclusively determines its function. In addition, they are not clear about the criteria by which semiconductor switches are to be selected for the given topology and type of conversion. This paper explains the approach to clarify the links between the topology and functions of the converter circuit as well as selection method for the required semiconductor switches. By using a simulation program, which contains model of the ideal switch, it is demonstrated that for the same topology, for example a single-phase bridge circuit, all four types of conversion can be realized. The selection methods of the actual semiconductor switches are based on simulation and analytical approach. By applying the proposed approach of clarifying the links between topology and function of the converter circuit, as well as applying the proposed methods for selection of semiconductor switches, the student's ability to grasp the basic power electronics concepts faster and more effectively is enhanced.
\end{abstract}

Keywords: power conversion circuits; power converter circuit topology and function; power electronics education; power semiconductor switch

\section{INTRODUCTION}

Students studying engineering applications of power electronics, obtain most of the required knowledge through one or two fundamental and several elective courses. The broad range of disciplines, numerous new terms, concepts and methods, presented from the very beginning present serious problems to the students. As a help in learning, authors of numerous papers suggest different approaches to interactive e-learning in power electronics [1-5]. The various approaches to teaching power electronics are classified starting with slide show with sound, audio text and movies, as well as numerical simulations, web simulations and interactive animations, all to help students be a more active participant in the teaching process. Computer simulation reduces costs in the device design phase, enables parametric analysis, but requires a good knowledge of component modelling, which is a problem for students at the basic level of learning especially because non-ideal behaviour of the components [6-8]. Interactive simulations have proven to be much more flexible for students use because animations run faster than numerical simulation, but students must follow specific instructions regarding the activation of specific elements of the selected converter topology [9, 10]. Also, project based learning method is emphasized as a method of self-learning in teaching of power electronics. As reported in [11-13], a project tasks are assigned to students from the specific converters applications in which they design control/power conversion circuits of the converter. This kind of power electronics teaching method provides student with a good practical space and occupies student's interest for the subject. However, this also requires well-established laboratories with expensive measuring equipment. Common to majority of the introductory part of power electronics textbooks is a careful and gradual introduction to the multidisciplinary area of power electronics [14-16]. Similarly to the cited papers and textbooks, in our courses we also define the basic concepts and their relationships as part of introduction to the field of power electronics. Using this approach we pay special attention to terms like the topology of the converter circuit, the function of the converter circuit and the semiconductor power switch.

We have noticed that majority of students initially think that the topology of the converter circuit exclusively determines its function. Another problem we have observed is misunderstanding of the criteria used for the selection of specific semiconductor components, once topology to perform the required conversion is selected. For that reasons, the second chapter of this paper describes our approach to explaining the relationship between the topology and the function of converter circuits. It is based on simple simulation experiments of a single phase bridge circuit by utilizing ideal switches. Four basic conversion types are simulated for this topology. In the third chapter characteristics of the ideal switch and idealised models for static characteristics of the most commonly used semiconductor components are given. The fourth chapter describes our approaches to explaining selection criteria of semiconductor components given the desired semiconductor switches within the studied converter topology. The fifth chapter provides some results of applying these approaches in teaching of power electronics basics.

\section{TOPOLOGY AND FUNCTION OF A CONVERTER CIRCUIT}

Topology of a converter circuit is determined by electrical connections of the electric switches. The term "function of the converter circuit" refers to the conversion type, i.e. rectification, inversion, and $\mathrm{DC} / \mathrm{DC}$ and $\mathrm{AC} / \mathrm{AC}$ conversion

\subsection{Topology and Topological State of a Converter Circuit}

Topology of a converter circuit is represented by an electric schematic. It is instructive to show to students who study basics of the power electronics that a schematic can be observed as "geometry on elastic base". As an example, different representations of electric schematic of single phase bridge circuit performing the rectification function can be used, as illustrated in Fig. 1. 


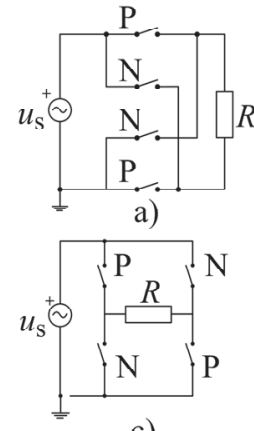

c)

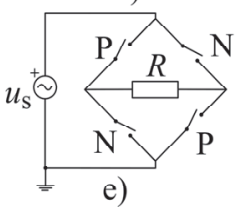

Figure 1 Different representations of electric schematic of single phase bridge circuit

Students can easily note that for all six schematics, connections between four ideal switches, the source and load are the same. It is interesting that the single phase bridge circuit can be represented even in the form of a tetrahedron. Once the term topology of the converter circuit is defined, students are guided to the fact that during performance of a certain conversion, topology is broken down into a series of topological states that are determined by its switching states. For the representation of the topological states, we use the so-called "characteristic working intervals table". This table lists all characteristic working intervals and shows which switches are switched on or off during a certain interval. To prepare this table, the ideal fully controlled switches are used. For example, for the topology shown in Fig. 1a, given a sinusoidal waveform voltage source, and a resistive load, and assuming that this topology performs the rectification function, students quickly notice that the ideal switches must operate as commutator. During the positive half-wave of the input sinusoidal voltage two $\mathrm{P}$ switches must be switched on, and during the negative half-wave of the input voltage two $\mathrm{N}$ switches must be switched on, as summarized in Tab. 1. In this way the full-wave rectified voltage is applied to the resistive load. Switching states when two upper or two lower switches are switched on at the same time are forbidden, since this would cause short circuiting of the voltage source.

Table 1 Characteristic working intervals table for single phase bridge rectifier circuit (C-closed; O-opened)

\begin{tabular}{|c|c|c|c|c|}
\hline Interval & $\mathrm{P}$ upper & $\mathrm{N}$ upper & $\mathrm{P}$ lower & $\mathrm{N}$ lower \\
\hline $0-\pi$ & $\mathrm{C}$ & $\mathrm{O}$ & $\mathrm{C}$ & $\mathrm{O}$ \\
\hline$\pi-2 \pi$ & $\mathrm{O}$ & $\mathrm{C}$ & $\mathrm{O}$ & $\mathrm{C}$ \\
\hline
\end{tabular}

\subsection{Converter Circuit Functions}

Students that for the first time meet the subject of power electronics think that only the converter circuit topology determines its function. For that reason, they try to memorise different electric schemes, without focusing on the general characteristics of the converter circuits.

One of the possible approaches to correct this misconception is to demonstrate that with only one topology all four basic energy conversion types can be achieved. Specific task for the students is to use the simulation program Plecs [18], for given input and output systems, to prepare models of a single phase bridge circuit with ideal switches as well as models of the control circuits (control algorithm for the switches). Without being burdened by a number and variations of the topology, as well with special characteristics of the semiconductor switches, the students concentrate on the algorithm to control the switches to use the single phase bridge circuit to achieve rectification, inversion, $\mathrm{DC} / \mathrm{DC}$ and $\mathrm{AC} / \mathrm{AC}$ conversion. Fig. 2 shows the illustration given to the students as a part of simulation exercise instructions. In all four cases there is a resistive load. The left side of the illustration shows the given waveforms of the source voltage. On the right side are the expected waveforms of output voltage. By performing this simulation exercise the students: (i) obtain initial information about basic types of the power electronics conversion, (ii) notice the relations between the topology and the topological states of the converters, (iii) learn that the converter function is not determined exclusively by its topology (iv) obtain initial insight into switch control algorithms required to achieve the basic conversion types. This simulation exercise is intended to further deepen the student's knowledge by introducing some new questions, such as: (i) how to improve harmonic content of the output voltage for each type of conversion, (ii) which power semiconductor components should be used to replace ideal switches for each type of conversion. Not expecting specific and correct answers to the first question during this early phase of instruction, it is suggested to the students to add a low-pass first or second order filter between output of the single phase bridge circuit and the resistive load in the case of rectification and $\mathrm{AC} / \mathrm{AC}$ and $\mathrm{DC} / \mathrm{DC}$ conversions. In the case of DC/AC conversion, we point out characteristics and role of the resonance filters and more complex methods of controlling switches i.e. more complex types of modulation. The questions related to specific power semiconductor components used in the converter circuits are answered in the next simulation exercise. By simulating the functional behaviour of the converter circuits, as it was done in the previous case of single phase bridge circuit for basic conversions, voltage and current waveforms of the ideal switches are obtained. By analysing these waveforms, the switching characteristics and voltage-current demands of the switches can be determined. Using this information, students can deduce which power semiconductor components can satisfy such demands and have the required switching characteristics. Before carrying out this simulation exercise, characteristics of the ideal switch must be defined, and the students must be informed about idealised models for the basic types of the power semiconductor components.

\section{IDEAL AND REAL SEMICONDUCTOR SWITCHES}

In the previous examples some characteristics of the ideal switch were implicitly assumed. Namely, it was assumed that it is fully controllable and that it can conduct current in both directions and block both voltage polarities. 

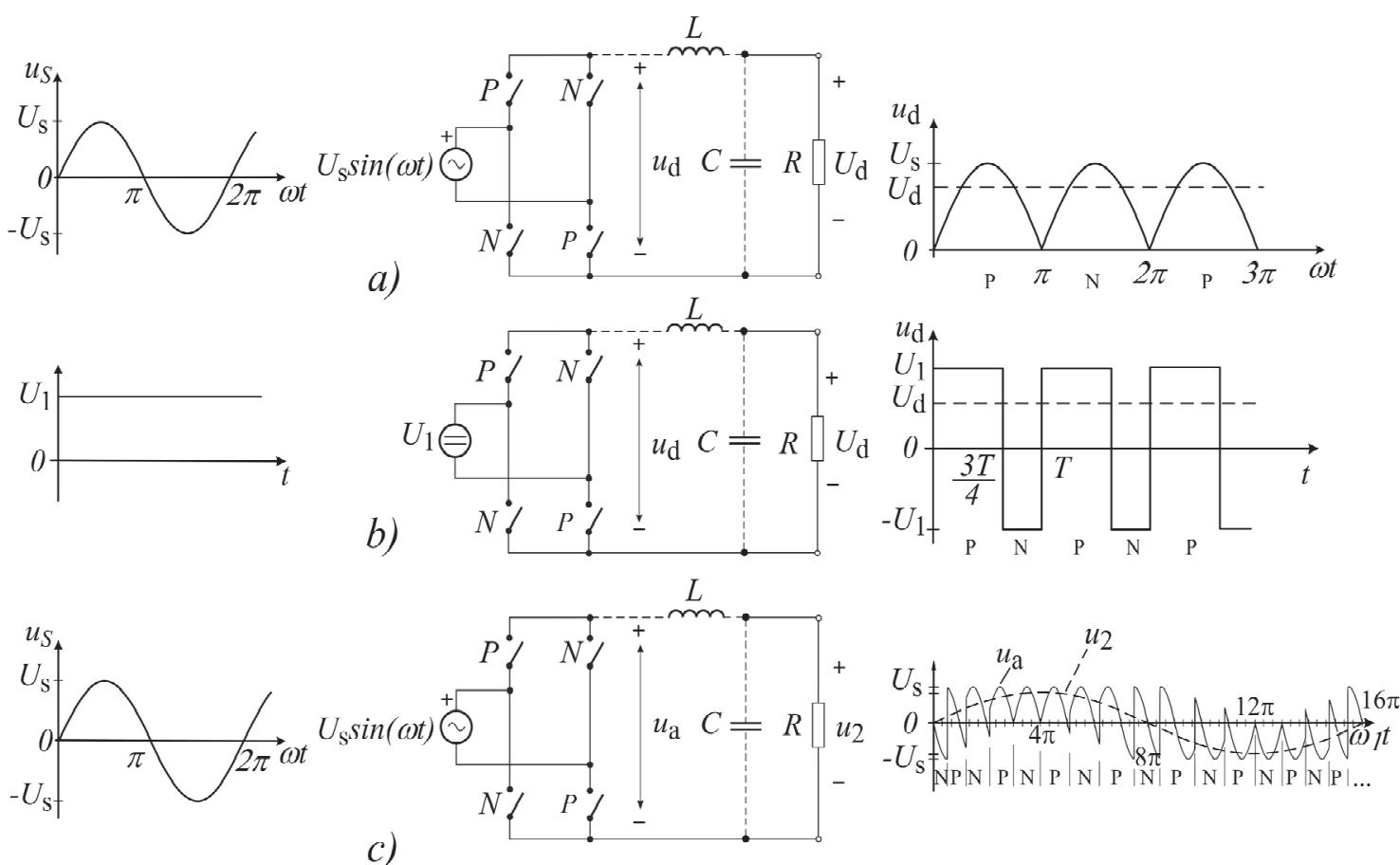

c)
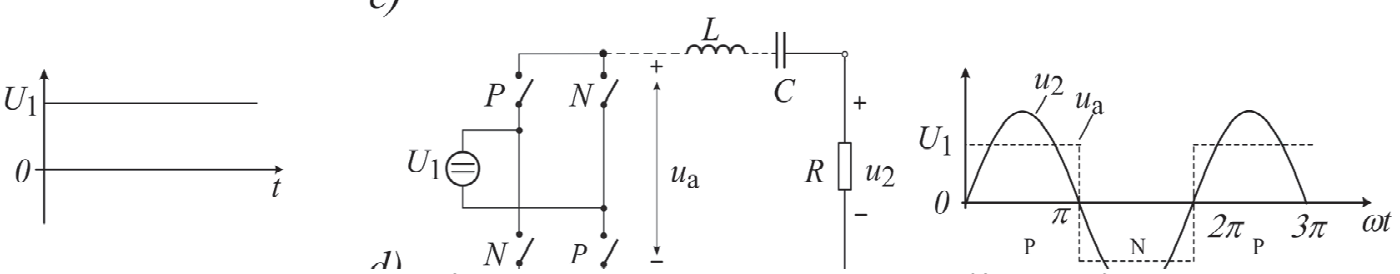

Figure 2 Topology of single phase bridge circuit in the implementation of four types of energy conversion

Being fully controllable means that the ideal switch can be switched on and off by the appropriate (logical) control signal. The ideal switch has no losses. Before selecting the actual power semiconductor components a reference direction of current and a reference voltage polarity of ideal switch have to be defined, as shown in Fig. 5 . The reference voltage polarity corresponds to the voltage drop when the switch conducts the current in the reference direction. During the teaching of power electronics, basics characteristics of the real power semiconductor components are represented by models of different complexities, $[16,17]$. It is convenient to first explain and use the static characteristics, and then later to introduce the dynamic characteristics by physical models. The static characteristics may be represented by idealised and ideal models, see Fig. 3.
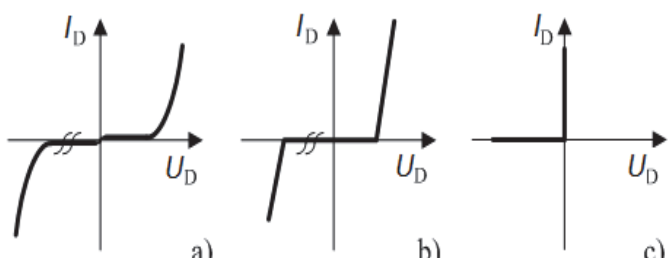

Figure 3 Static characteristics of diodes: a) real; b) idealised; c) ideal

Additionally, the switching characteristics must also be known, i.e. is it the non-controllable, semi-controllable or fully-controllable. During this phase of teaching it is not important to define the control signal types. Ideal static characteristics of the semiconductor components determine their operating quadrants, i.e. define the permitted current directions and voltage polarities. Fig. 4 shows the operating quadrants of diode, thyristor, bipolar transistor (BJT), insulated gate bipolar transistor (IGBT), and power MOSFET.

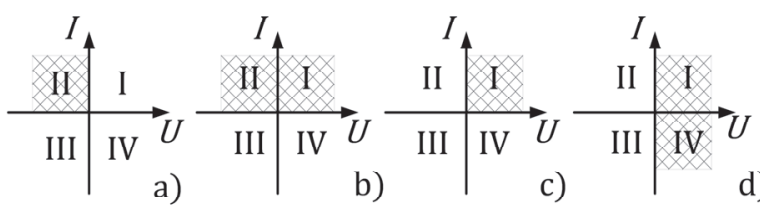

Figure 4 Operating quadrants for a) diode; b) thyristor; c) BJT and IGBT; d) power MOSFET

Ideal static characteristics of the diode in Fig. 3 show that the diode can hold negative (reverse) voltage and conduct a positive current. Negative voltage and positive current determine the II. quadrant of the coordinate system in the $I-U$ (current-voltage) plane. After the operating quadrants for the power semiconductor components are defined their characteristics must be characterized from the point of controllability.

The diode is the only example of non-controllable component that switches on when its voltage becomes positive, and switches off either because of commutation or because the current drops to zero.

The thyristor is example of the semi-controllable component that switches on when its voltage is positive and when the appropriate signal is applied to the gate. It switches off either because of commutation or because the current drops to zero. The thyristor is an example of the semi-controllable component that switches on when its voltage is positive and when the appropriate signal is 
applied to the gate. It switches off either because of commutation or because the current drops to zero.

Power transistors are examples of the fully-controllable components. Tab. 2 shows the operating quadrants and switching characteristics of some of the most commonly used power semiconductor components. The same table also shows the antiparallel combinations of the transistor and diode (example of hybrid switch) that is used if the required operating quadrants cannot be achieved using only one semiconductor component.

Table 2 Some power semiconductor components, operating quadrants and controllability characteristics

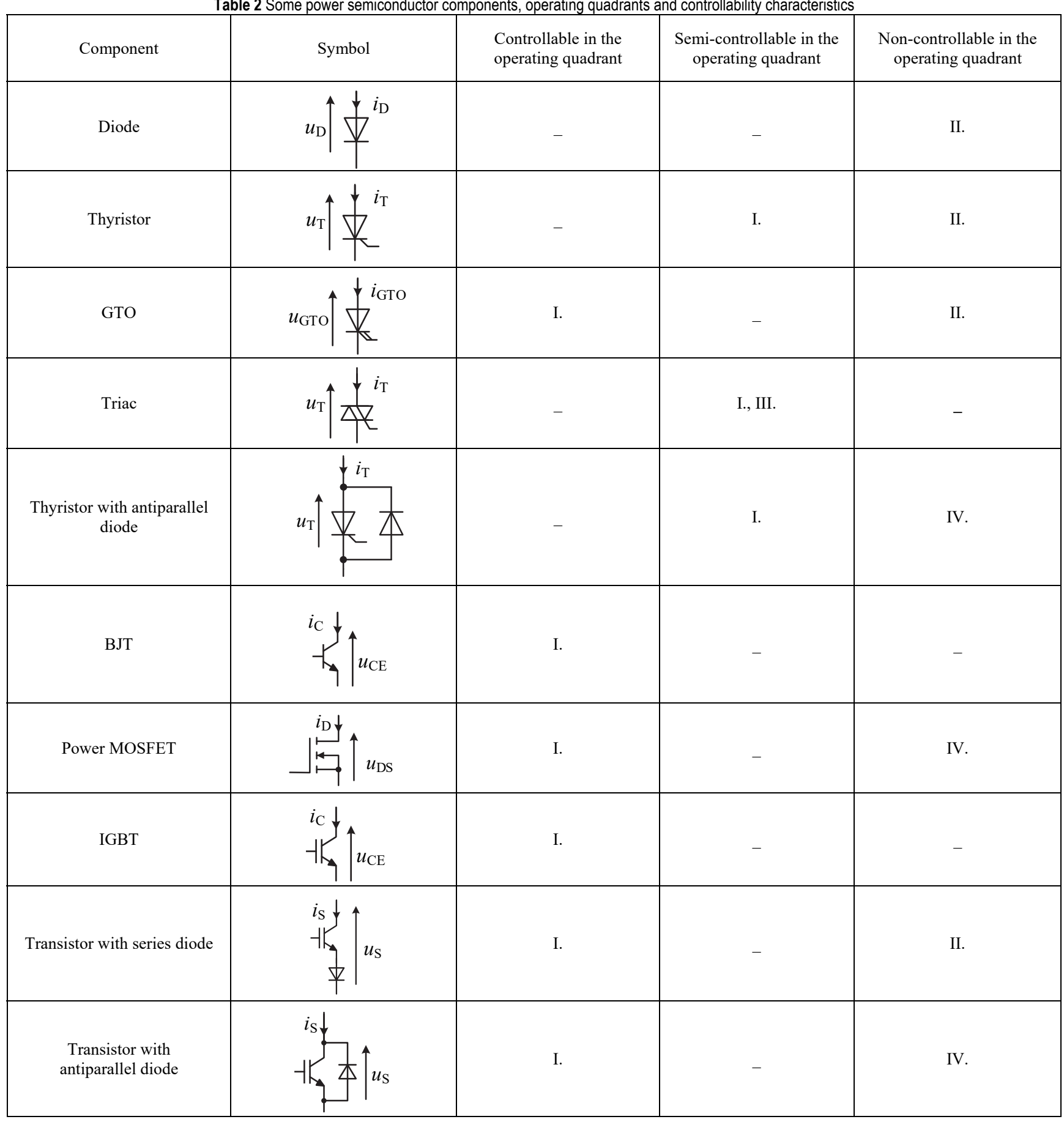

\section{SELECTION METHODS OF POWER SEMICONDUCTOR COMPONENTS}

After the ideal static models and the switching characteristics of the power semiconductor components shown in Tab. 2 are explained, students learn how to select semiconductor components needed to achieve the real converter circuit. For this purpose two different approaches are used: simulation approach and analytical approach.

\subsection{Selection Method by using a Simulation Approach}

This method is using a simulated electrical behaviour of the converter circuit with ideal fully-controllable switches to determine the voltage and current waveforms on the switches. After the voltage and current waveforms are obtained by means of simulation, the next steps are applied: (i) identification of the voltage-current characteristics of the switch, (ii) identification of the switching characteristics of the switch. To illustrate the method, the 
example of selecting power semiconductor components for series resonant inverter will be used, see Fig. 2d. For this type of converter, depending on the character of the load (resistive, inductive, capacitive), different semiconductor components can be used, [19-22].

\subsubsection{Series Resonant Inverter with Inductive Load}

Simulation model of a series resonant inverter, prepared with program package Plecs, is shown in Fig. 5. Ideal switches are still used with reference current direction and reference voltage polarity. Note that Fig. 5 does not show the control circuit model. For given values of the input DC voltage (e.g., $U \mathrm{dc}=32 \mathrm{~V})$, resistive load $R(0.32$ $\Omega)$ and the LC elements of the series resonance circuit $(L=$ $64 \mu \mathrm{H}, C=1 \mu \mathrm{F}$ ), functional behaviour of the circuit is simulated. The control circuit model generates control signals for the switch $\mathrm{S} 1-\mathrm{S} 4$ in such a manner that $u_{\mathrm{LOAD}}$ is square waveform voltage with the frequency close to the resonant frequency of the series oscillating circuit. Upper part of the Fig. 6 shows the voltage and current waveforms of the load ( $\left.u_{\mathrm{LOAD}}, i_{\mathrm{LOAD}}\right)$ when the switching frequency of the resonant inverter is higher than the resonant frequency of the series RLC circuit. For such relation of frequencies, it is evident that the current lags the load voltage.

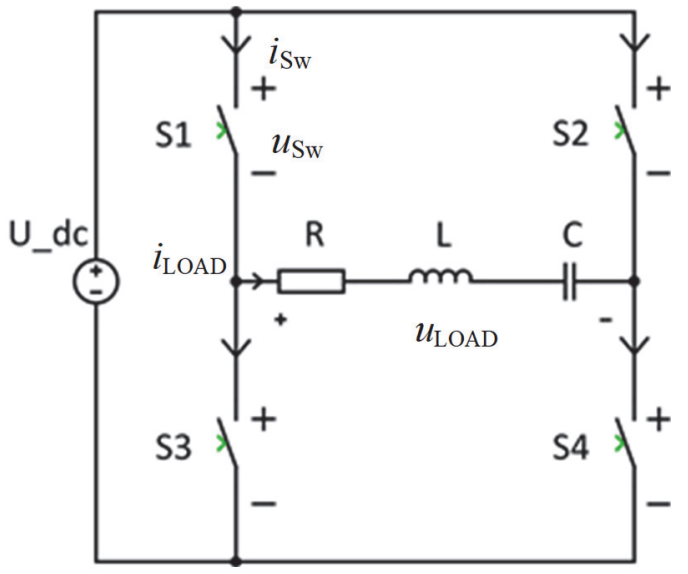

Figure 5 Model of a series resonant inverter

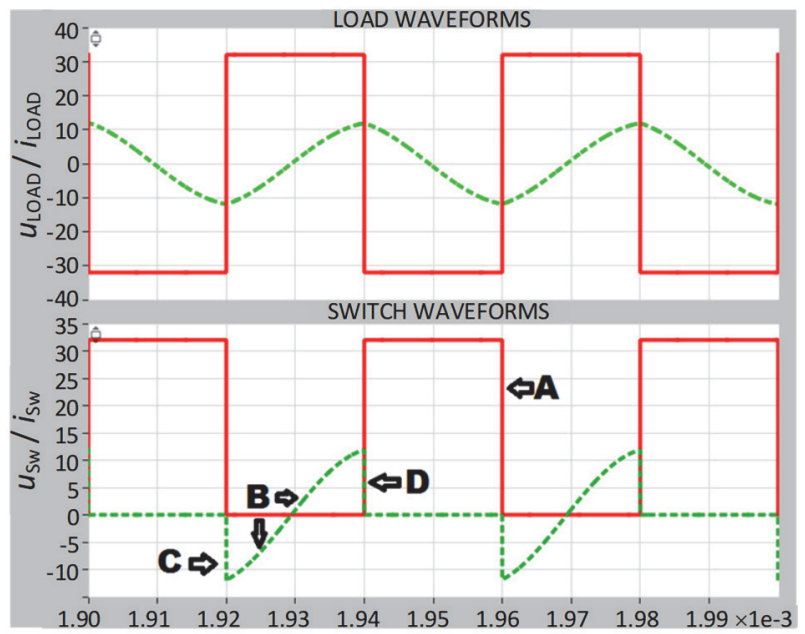

Figure 6 Voltage and current waveforms of the load (ULOAD, iLOAD), and of the switches $\left(u_{S_{w}}, i_{\mathrm{S} w}\right)$ at the switching frequency greater than the resonant $\left(\omega_{s}>\right.$ $\left.\omega_{0}\right)$, the load has inductive character

The lower part of Fig. 6 shows the voltage and current waveforms of the switches $\mathrm{S} 1$ and $\mathrm{S} 4\left(u_{\mathrm{Sw}}, i_{\mathrm{SW}}\right)$ that are used for identification of the voltage-current characteristics and switching characteristics of the switches. In the case of inductive character of the load, it follows that the switches:

- hold only the positive voltage (detail A)

- $\quad$ conduct negative and positive current (detail B)

- $\quad$ switch-on negative current (detail C)

- $\quad$ switch-off positive current that is transferred to the complementary switches (detail D).

Due to the voltage-current characteristics of the switches (they hold only the positive voltage and conduct both negative and positive current), the conclusion follows that the switches operate in I. and IV. quadrants. Due to switching off the positive current, where commutation caused by the power supply network is not active in this topology, the switch must be fully-controllable in the I. quadrant. Inspection of characteristics of the power semiconductor components from Tab. 2 shows that two solutions are possible; (i) using a power MOSFET (with built-in diode), or (ii) using a hybrid switch consisting of antiparallel combination of transistor and diode. The final selection of the switch depends on the technical factors (power, voltage load, operating frequency). In this case, hybrid switch with IGBT transistor is selected, see Fig. 7.

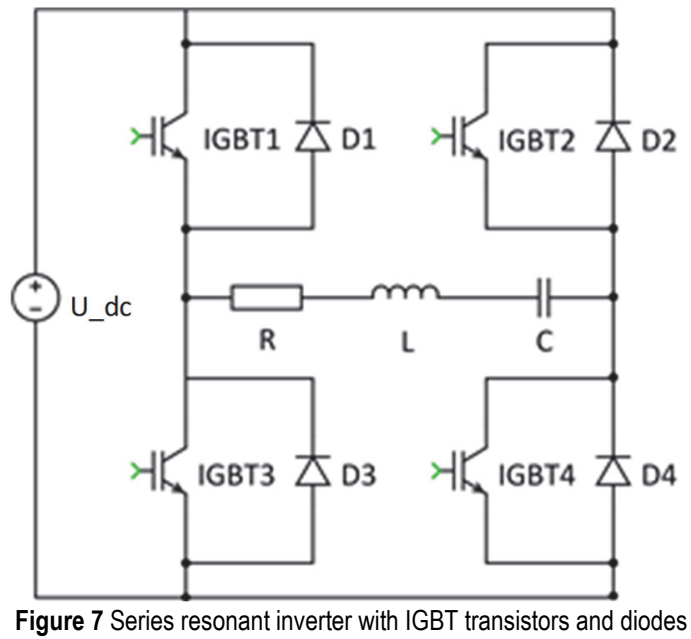

\subsubsection{Series Resonant Inverter with Capacitive Load}

If the resonant inverter is used at the switching frequencies that are lower than the resonant frequency of the series RLC circuit, the series RLC circuit behaves as a capacitive load. In that case, the voltage and current waveforms of the load are shown in the upper part of Fig. 8. In the lower part of Fig. 8, voltage and current waveforms of switches $\mathrm{S}_{1}$ and $\mathrm{S}_{4}\left(u_{\mathrm{SW}}, i_{\mathrm{SW}}\right)$ are shown in case when the series RLC circuit behaves as a capacitive load.

Inspection of voltage and current waveforms of switches S1 and S4, for the case of a capacitive load of the series resonant inverter, shows that the switches:

- hold only the positive voltage (detail A)

- conduct both positive and negative current (detail B)

- switch-on the positive current (detail C)

- $\quad$ switch-off the negative current if a positive voltage appears (detail D). 


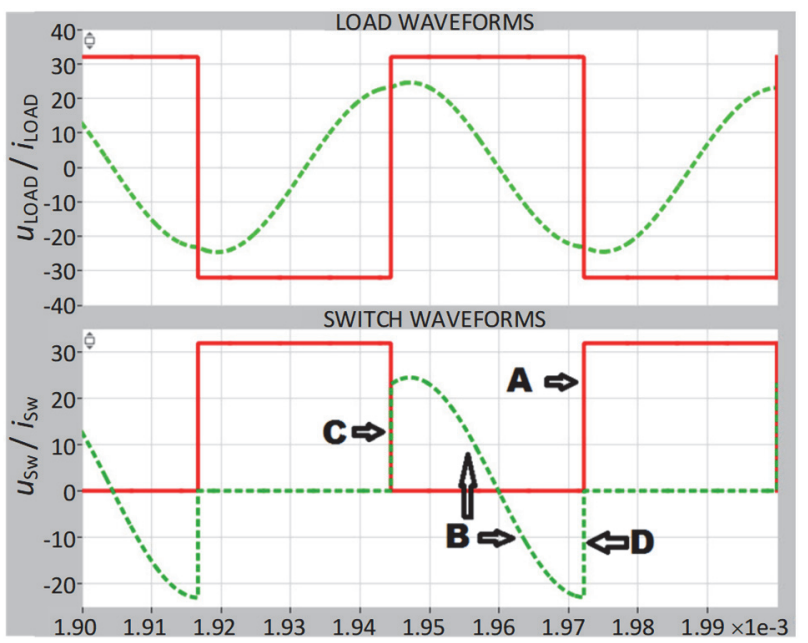

Figure 8 Voltage and current waveforms of the load (U LOAD, i LOAD), and of the switches $\left(u_{\mathrm{Sw}}, i_{\mathrm{Sw}}\right)$ at the switching frequency lower than the resonant one $\left(\omega_{\mathrm{s}}<\right.$ $\left.\omega_{0}\right)$, the load has capacitive character

Due to the voltage-current characteristics of the switches (hold only positive voltage and conduct positive and negative current), the conclusion follows that such switches operate in I. and IV. quadrants. The switches switch on the positive current, but during conduction automatically switch off if current drops to zero, so they do not have to be switched off (fully-controllable). It is sufficient that they are semi-controllable.

Inspection of the characteristics of power semiconductor components from Tab. 2 shows that three solutions are possible; (i) using a power MOSFET (with built-in diode), (ii) using a hybrid switch consisting of antiparallel combination of transistors and diodes, (iii) using a hybrid switch consisting of antiparallel combination of thyristors and diodes. In this case, the hybrid thyristor-diode switch is selected, see Fig. 9. The primary reason for selecting this hybrid switch is possibility to use this example to teach the students about the concept of recovery time of the thyristor.

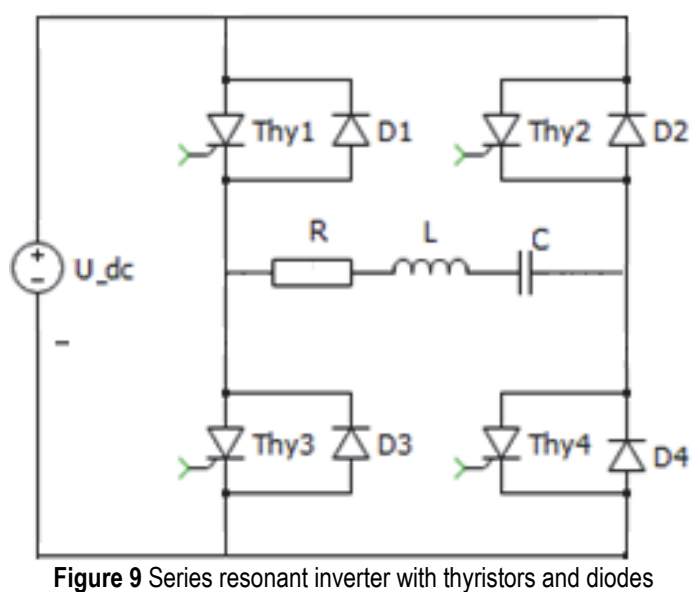

\subsection{Selection Method by using an Analytical Approach}

Another approach to determining which power semiconductor components can be used for chosen topology and to achieve desired conversion stems from the circuit theory point of view. The characteristic waveforms of switches are obtained by using an analytical approach and by writing the state equations based on Kirchhoff's laws. Students are familiar with writing state equations of conversion circuit model and this approach allows them to obtain characteristic currents and voltages of semiconductor components as by using simulation programs. A DC/DC conversion i.e. a 2-quadrant stepdown converter, was chosen as an example of this approach.

\subsubsection{Two-Quadrant Step-Down DC/DC Converter}

Model of the two-quadrant step-down DC/DC converter and the desired voltage and current waveforms on the inductive load are shown in Fig. 10. Ideal switches are still used with reference current direction and reference voltage polarity. The assumptions of the analysis are:

- symmetrical control [23];D= $\frac{t_{\mathrm{ONSw} 1}}{T_{\mathrm{s}}}=\frac{t_{\mathrm{ONSw} 4}}{T_{\mathrm{s}}}$,

where are: $D$ - duty cycle, $T_{\mathrm{s}}$ - switching period and $t_{\mathrm{ONSw}}$ - time when switch is closed,

- $\quad$ parameters of load are chosen in the way that $L / R » T_{\mathrm{s}}$, which ensures continuous current of the load,

- interval of choosing duty cycle is: $1 / 2<D<1$, due to the step down topology: $U_{-} \mathrm{dc}>u_{\mathrm{LOAD}}$.

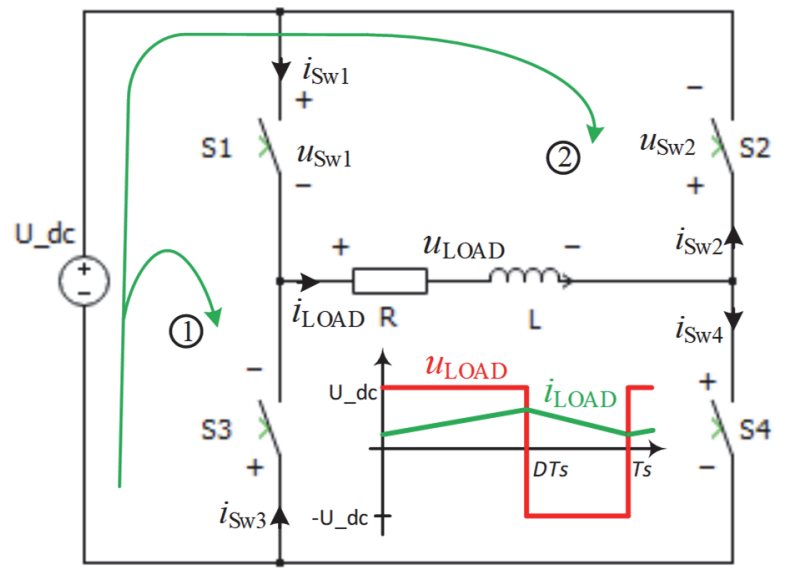

Figure 10 Model of a 2-quadrant step down DC/DC converter

There are two intervals in analysis, Tab. 3.

Table 3 Characteristic working intervals for 2-quadrant $\mathrm{DC} / \mathrm{DC}$ converter ( $\mathrm{C}$ - closed; $\mathrm{O}$ - opened)

\begin{tabular}{|c|c|c|c|c|}
\hline Interval & $\mathrm{S} 1$ & $\mathrm{~S} 2$ & $\mathrm{~S} 3$ & $\mathrm{~S} 4$ \\
\hline $0-D T_{\mathrm{s}}$ & $\mathrm{C}$ & $\mathrm{O}$ & $\mathrm{O}$ & $\mathrm{C}$ \\
\hline$D T_{\mathrm{s}}-T_{\mathrm{s}}$ & $\mathrm{O}$ & $\mathrm{C}$ & $\mathrm{C}$ & $\mathrm{O}$ \\
\hline
\end{tabular}

By writing Kirchhoff's law of voltages for loops 1 and 2, (see Fig. 10) for first interval, it is obtained:

loop 1; $U \mathrm{dc}-u_{\mathrm{Sw} 1}+u_{\mathrm{Sw} 3}=0$

loop $2 ; \quad U_{-} \mathrm{dc}+u_{\mathrm{Sw} 2}-u_{\mathrm{Sw} 4}=0$

By taking in consideration working intervals, and voltage of closed ideal switch; $u_{\mathrm{Sw} 1}=u_{\mathrm{Sw} 4}=0$, it is obviously: $u_{\mathrm{Sw} 3}=u_{\mathrm{Sw} 2}=-U_{-}$dc. Similarly, it can be shown for second interval; $u_{\mathrm{Sw} 1}=\bar{u}_{\mathrm{Sw} 4}=U$ dc. The characteristic waveforms are shown in Fig. 11. It follows that switches $\mathrm{S} 1$ and S4 hold only positive voltage and conduct positive current, whereas ideal switches S2 and S3 hold only negative voltage and conduct positive current. Due to the 
voltage-current characteristics of the switches in Fig. 4, a conclusion follows that switches $\mathrm{S} 1$ and S4 operate in I quadrant and switches S2 and S3 operate in II quadrant. To achieve a steady state, it is sufficient to select the first two as fully controllable and the other two as non-controllable.

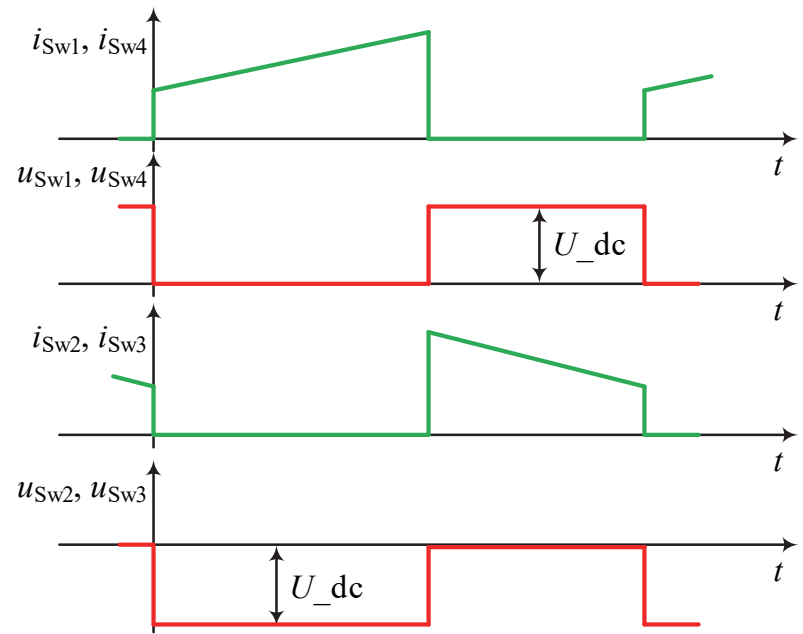

Figure 11 Voltage and current waveforms of switches obtained by analysis

Inspection of characteristics of the power semiconductor components from Tab. 2 implies that switches $\mathrm{S} 1$ and $\mathrm{S} 4$ can be realized as IGBTs and switches $\mathrm{S} 2$ and $\mathrm{S} 3$ as diodes.

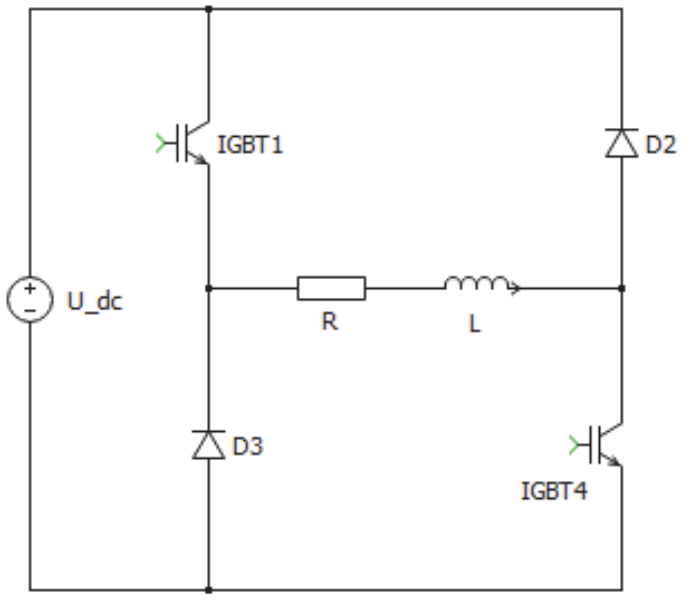

Figure 12 Two-quadrant step down DC/DC converters with IGBT's and diodes

\section{EDUCATIONAL RESULTS}

The approaches described above were tested during the course "Power electronics" which is a part of Studies of power efficiency and renewable power sources. During the first offering of the course, the classical approach was used; students were first taught the basic types of the power semiconductor switches and their characteristics, and after that they were taught the basic types of conversions in the power electronics. The operation of typical circuits was described and analysed based on the fully defined topologies and functions of the converters. To verify the student's knowledge and competencies, we used to ask 2 characteristic sets of tasks. The first set of tasks covered the connection of defined converter topologies with the voltage and current waveforms of the loads for characteristic types of conversion. The second set of tasks covered the selection of the characteristic voltage-current relations on the power semiconductor switches for typical power converters (e.g. from possible 3 or 4 suggested current-voltage waveforms students have to select a waveform that corresponds to the current-voltage loading on an IGBT/diode switch for a single-phase bridge inverter and the square output voltage). The percentage of correct solutions of such tasks, using the sample of 42 students, was $37 \%$. Also, final testing of students at the end of the semester gave success rate of $57 \%$. These results indicated that students cannot cope with the large number of different circuit topologies, nor with the cases of the same topologies constructed from different types of the semiconductor power switches. The students were learning by heart the convertor schemes and tried to relate them to their functions. During the second year of offering the course we decided to introduce the above described approaches and methods, before going into details of individual conversion types. The students were asked the same or similar questions and given similar tasks as during the year before. The percentage of correctly solved tasks was $65 \%$ on a sample of 48 students. Also, final testing at the end of semester gave success rate of $75 \%$. Similar results were also achieved during the third year of teaching the course, where the success rate was $64 \%$, with the sample size of 32 students. The final testing at the end of semester gave success rate of $74 \%$, Tab. 4 .

Table 4 A survey of student results using old and new method

\begin{tabular}{|c|c|c|c|}
\hline & $\begin{array}{c}\text { Old } \\
\text { method }\end{array}$ & $\begin{array}{c}\text { New method 1st } \\
\text { Y }\end{array}$ & $\begin{array}{c}\text { New method 2nd } \\
\text { Y }\end{array}$ \\
\hline Dedicated tasks & $37 \%$ & $65 \%$ & $64 \%$ \\
\hline Final exam & $57 \%$ & $75 \%$ & $74 \%$ \\
\hline
\end{tabular}

\section{CONCLUSION}

During teaching of the basics of power electronics, terms such as topology and topological state of the converter circuit, functions of the converter circuit and the power semiconductor switch are defined. This paper describes the approach to introductory laboratory exercises which points out that with the same topology, but by using different controlling methods and power semiconductor switches, all four types of conversions can be achieved. This approach clearly shows that the function of the converter circuit, in addition to its topology, is determined by the method of controlling the switches and type of switches. Applying the approaches described in this paper, students can determine which power semiconductor components can be used in the given converter topology to achieve the desired conversion. These methods are demonstrated on example of the series resonance inverter for capacitive and inductive characters of the load as well as for 2-quadrant $\mathrm{DC} / \mathrm{DC}$ converter. As evidenced by significant improvements in student test scores and passing rates, we believe that this novel approach results in faster and better acquisition of knowledge needed in elementary power electronics courses and follow-on courses.

\section{REFERENCES}

[1] Drofenik, U., Kolar, J. W., van Duijsen, P. J., \& Bauer, P. (2001). New Web-Based Interactive E-Learning in Power Electronics and Electrical Machines. Conf. Record of the 
2001 IEEE Industry Applications Conf. 36th IAS Annual Meeting, 3, 1858 - 1865. https://doi.org/10.1109/IAS.2001.955784

[2] Fernández, C., García, O., Cobos, J. A., \& Uceda, J. (2002). Self learning Laboratory Set up for Teaching Power Electronics Combining Simulations and Measurement. Int. Conf. EPE-PEMC'2002. https://doi.org/10.1109/PSEC.2002.1022494

[3] Agelidis, V. G. (2005). The Future of Power Electronics/Power Engineering Education: Challenges and Opportunities. PEEW/PESC, 1-6. https://doi.org/10.1109/PEEW.2005.1567584

[4] Hamar, J., Funato, H., \& Ogasawara, S. (2005). E-Learning in Power Electronics: The State of the Art. IPEC 05.

[5] Liao, W., Liu, J., \& Wang, S. (2008). Research of Multisim in the experiment teaching. International Conference on Computer Science and Software Engineering, CSSE 2008, 515-517.

[6] Bauer, P. \& Kolar, J. (2003). Teaching Power Electronics in 21 Century. EPE Journal. https://doi.org/10.1080/09398368.2003.11463546

[7] Clovis, A., Petry, A., Moia, J., Pacheco, F. S., Alves, G. R., \& Felgueiras, M. C. (2014). Streamlining Power Electronics Teaching. XI Technologies Applied to Electronics Teaching (TAEE). https://doi.org/10.1109/TAEE.2014.6900150

[8] Coube, P. R., Waghmare, T. B., \& Katre, S. S. (2016), Analysis and implementation of various teaching methodologies in power electronics for Electrical Engineering students at SPPU, Pune. International journal of innovations in engineering research and technology, $3(10)$.

[9] Drofenik, U. \& Kolar, J. W. (2002). Survey of Modern Approaches of Education in Power Electronics. Seventeenth Annual IEEE Applied Power Electronics Conference and Exposition-2002. https://doi.org/10.1109/APEC.2002.989329

[10] Flores-Arias, J. M., Moreno-Munoz, A., Bellido, F. J., \& Linan, M. (2010). Active learning in Power Electronic. IEEE EDUCON 2010 Conference. https://doi.org/10.1109/EDUCON.2010.5492356

[11] Huang, Z. (2016). Teaching Reform and Exploration of Power Electronic Technology Course based on Project Teaching Method. International Conference on Education, Management Science and Economics (ICEMSE 2016). https://doi.org/10.2991/icemse-16.2016.79

[12] Pires, V. F., Pires, A. J., \& Dias, O. P. (2011). Self-learning as tool for teaching Power Electronic. 5th IEEE International Conference on E-Learning in Industrial Electronics (ICELIE). https://doi.org/10.1109/ICELIE.2011.6130035

[13] Zhang, Z., Hansen, C. T., \& Andersen, M. A. E. (2016). Teaching Power Electronics with designed-oriented and project based learning method. IEEE Transactions on Education, 59(1). https://doi.org/10.1109/TE.2015.2426674

[14] Kassakian, J. G., Schlecht, M. F., \& Verghese, G. C. (1991). Principles of power electronics. Addison-Wesley Publishing Company, Inc., 1-54.

[15] Holmes, D. G. \& Lipo, T. A. (2003). Pulse width modulation for power converters - principles and practice. IEEE Press, Wiley interscience, 1-7. https://doi.org/10.1109/9780470546284

[16] Mohan, N., Undeland, T. M., \& Robins, W. P. (1995). Power electronics - Converters, Applications, and design. Second edition, John Wiley and sons, INC., 3-76.

[17] Hart, D. W. (1997). Introduction to power electronics. Prentice Hall, 1-64

[18] See https://www.plexim.com/files/plecsmanual.pdf

[19] Platek, M. \& Waradzyn, Z. (2006). Operation modes of fullbridge voltage-source series resonant inverter with PFM control for induction heating applications. Elektrotechnika $i$ elektronika, Tom 25.
[20] Qi, X., Peng, Y., \& Li, Y. (2012). Parameters Design of Series Resonant Inverter Circuit. 2012 International Conference on Applied Physics and Industrial Engineering, Physics Procedia 24, 133-138.

https://doi.org/10.1016/j.phpro.2012.02.021

[21] Agrawal, A., Verma, R., Gupta, A., \& Jaiswal, A. (2013). Simulation of Series Resonant Inverter with Unidirectional Switches via Multisim. 2013 International Conference on Power, Energy and Control (ICPEC). https://doi.org/10.1109/ICPEC.2013.6527667

[22] Sahiti, K. \& Geetha, V. (2015). Simulation of series resonant inverter using pulse density modulation. ARPN Journal of Engineering and Applied Sciences, 10(7).

[23] Tiwari, J. P. \& Barve, A. (2014). Comparison between Symmetrical and Asymmetrical Controlled Three-Phase High Frequency Isolated DC-DC Converter. International Journal of Electrical, Electronics and Computer Engineering, 3(1), 116-121.

\section{Contact information}

Viktor ŠUNDE, Full professor

(Corresponding author)

University of Zagreb,

Faculty of electrical engineering and computing,

Unska 3, 10000 Zagreb, Croatia

E-mail: viktor.sunde@fer.hr

Željko JAKOPOVIĆ, Full professor

University of Zagreb,

Faculty of electrical engineering and computing,

Unska 3, 10000 Zagreb, Croatia

E-mail: zeljko.jakopovic@fer.hr

Zvonko BENČı́́, Full professor

University of Zagreb,

Faculty of electrical engineering and computing,

Unska 3, 10000 Zagreb, Croatia

E-mail: zvonko.bencic@fer.hr

Denis PELIN, Full professor

Josip Juraj Strossmayer University of Osijek,

Faculty of Electrical Engineering,

Computer Science and Information Technology Osijek,

Kneza Trpimira 2B, 31000 Osijek, Croatia

E-mail: denis.pelin@ferit.hr 